Journal of Organometallic Chemistry, 371 (1989) 197-203

Elsevier Sequoia S.A., Lausanne - Printed in The Netherlands

JOM 09909

\title{
The site selectivity of hydride ligand in tungsten-triosmium clusters: the crystal structure and the solution dynamics of $\left(\mathrm{C}_{5} \mathrm{Me}_{5}\right) \mathrm{WOs}_{3}(\mathrm{CO})_{12} \mathrm{H}$
}

\author{
Shie-Ming Peng **, Gene-Hsiang Lee \\ Department of Chemistry, National Taiwan University, Taipei 10764, (Taiwan, R.O.C.)
}

\author{
Yun Chi *, Chu-Lan Peng, and Ling-shwu Hwang \\ Department of Chemistry, National Tsing Hua University, Hsinchu 30043, (Taiwan, R.O.C.) \\ (Received February 6th, 1989)
}

\begin{abstract}
The solid-state structure of a tetranuclear mixed-metal cluster $\left(\mathrm{C}_{5} \mathrm{Me}_{5}\right) \mathrm{WOs}_{3}-$ $(\mathrm{CO})_{12} \mathrm{H}(\mathbf{2 b})$ which has hydride ligand bridging across a $\mathrm{W}-\mathrm{Os}$ bond is presented. In solution, the isomer adopting the solid-state structure is in equilibrium with a second isomer (2a) in which the hydride is associated with an Os-Os edge. Complex 2 crystallizes in the orthorhombic space group Pna $2_{1}$, with $a$ 21.598(6), b 8.973(4), $c$ 14.121(4) $\AA, Z=4 ; 2260$ observed reflections with $I>3 \sigma(I)$ were used in the refinement. The $R$ values converged to $R_{\mathrm{F}}=0.023, R_{\mathrm{w}}=0.018$ and GOF $=1.500$.
\end{abstract}

\section{Introduction}

The chemistry of the mixed-metal clusters of transition metals has been the subject of much research [1], because the reactivities of the various metals present in mixed metal clusters can show reactivity patterns and/or structures very different from those of their homometallic analogues. Owing to the high thermal stability of the osmium containing compounds, many papers dealing with the synthesis of mixed-metal clusters containing a triosmium unit have appeared [2].

A decade ago, Shapley and coworkers [3] reported the synthesis of a tungsten-triosmium cluster, $\mathrm{CpWOs}{ }_{3}(\mathrm{CO})_{12} \mathrm{H}(1)$ by a condensation of $\mathrm{Os}_{3}(\mathrm{CO})_{10}\left(\mathrm{CH}_{3} \mathrm{CN}\right)_{2}$ with $\mathrm{CpW}(\mathrm{CO})_{3} \mathrm{H}$. The structure of 1 is shown in Scheme 1. Starting from this complex, our group has successfully prepared a polynuclear cluster oxide complex, $\mathrm{CpWO}_{3}(\mathrm{CO})_{9}(\mu-\mathrm{O})_{2} \mathrm{H}$ [4]. During our investigation of this interesting oxidation

\footnotetext{
* To whom inquiries concerning the X-ray crystallographic work should be addressed.
} 


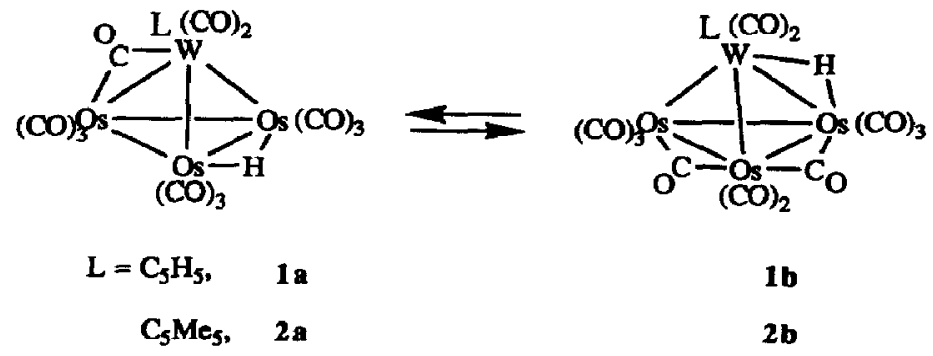

Scheme 1 .

reaction, we noticed that complex 1 displays two hydride resonances at $\delta-18.63$ and $-21.82\left(J_{\mathrm{W}-\mathrm{II}}=43 \mathrm{~Hz}\right)$ with relative intensities $3: 1\left(400 \mathrm{MHz}, \mathrm{CD}_{2} \mathrm{Cl}_{2}, \mathrm{RT}\right)$, suggesting the presence of two interconvertible isomers in solution. The downfield resonance is clearly attributable to the isomer adopting a solid-state structure, but the structure of the second isomer, which possesses a $\mathbf{W}-\mathrm{H}-\mathrm{Os}$ interaction, is at present unknown. In order to examine the structure of the unknown isomer, we decided to prepare the relevant pentamethylcyclopentadienyl analogue, $\mathrm{Cp}^{\star} \mathrm{WOs}_{3}(\mathrm{CO})_{12} \mathrm{H}\left(2, \mathrm{Cp}^{\star}=\mathrm{C}_{5} \mathrm{Me}_{5}\right)$.

\section{Results and discussion}

Complex 2 can be prepared by the condensation of $\mathrm{Os}_{3}(\mathrm{CO})_{10}\left(\mathrm{CH}_{3} \mathrm{CN}\right)_{2}$ with $\left.\mathrm{Cp} \mathrm{p}^{\star} \mathrm{COO}\right)_{3} \mathrm{H}$. The ${ }^{1} \mathrm{H}$ NMR spectrum exhibits two hydride resonances at $\delta$ -18.22 and $-20.93\left(J_{\mathrm{W}-\mathrm{H}}=41 \mathrm{~Hz}\right)$ with relative intensities $1: 2.1$ at room temperature, suggesting that the structurally uncharacterized isomer becomes the dominant species in solution. Encouraged by this discovery, we then carried out a single crystal X-ray diffraction study.

The molecular structure of $\mathbf{2 b}$ is shown in Figure 1 while interatomic distances and angles are listed in Table 1. The tungsten atom and the three osmium atoms define a distorted tetrahedral core framework which is associated with the expected 60 outer valence electrons. The tungsten atom is coordinated to a cyclopentadienyl ligand and two $\mathrm{CO}$ ligands and the three basal osmium atoms are associated with eight terminal and two semi-bridging $\mathrm{CO}$ ligands. The three basal Os-Os bond distances are almost identical, but the $\mathrm{W}-\mathrm{Os}(1)$ distance $(3.0734 \AA$ ) is substantially longer than the other two W-Os bonding interactions, $W-O s(2)=2.9038 \AA$ and $\mathrm{W}-\mathrm{Os}(3)=2.9074 \AA$. The hydride ligand, which bridges the longest $\mathrm{W}-\mathrm{Os}(1)$ bond, was located on the difference electron-density map. The observed $W-H$ distance $(1.966 \AA)$ is approximately $0.3 \AA$ greater than the corresponding $\operatorname{Os}(1)-H(1.679 \AA)$ distance, suggesting that the bonding mode of the hydride ligand involves a unique, asymmetric, three-center two-electron $\mathrm{W}-\mathrm{H}-\mathrm{O}$ interaction.

An additional feature of interest is the presence of three semi bridging carbonyl ligands [5]. The first $\mathrm{C}(12)-\mathrm{O}(12)$, coordinates to the $\mathrm{W}$ atom while also interacting very weakly with the $\operatorname{Os}(2)$ atom $(\mathrm{W}-\mathrm{C}(12)=1.983(18) \AA ; \quad \operatorname{Os}(2)-\mathrm{C}(12)=$ $2.844(17) \AA$ ). The bond angle, $W-C(12)-O(12)=167.5(14)^{\circ}$, suggests that this $C O$ ligand can almost be classified as a semi-bridging ligand. The second, $C(7)-O(7)$, spans the $\mathrm{Os}(3)-\mathrm{Os}(1)$ linkage with $\mathrm{Os}(3)-\mathrm{C}(7)=1.982 \AA$ and $\mathrm{Os}(1)-\mathrm{C}(7)=2.583$ $\AA$; the third, $\mathrm{C}(10)-\mathrm{O}(10)$, associates with the $\mathrm{Os}(3)-\mathrm{Os}(2)$ edge, with $\mathrm{Os}(3)-\mathrm{C}(10)$ 


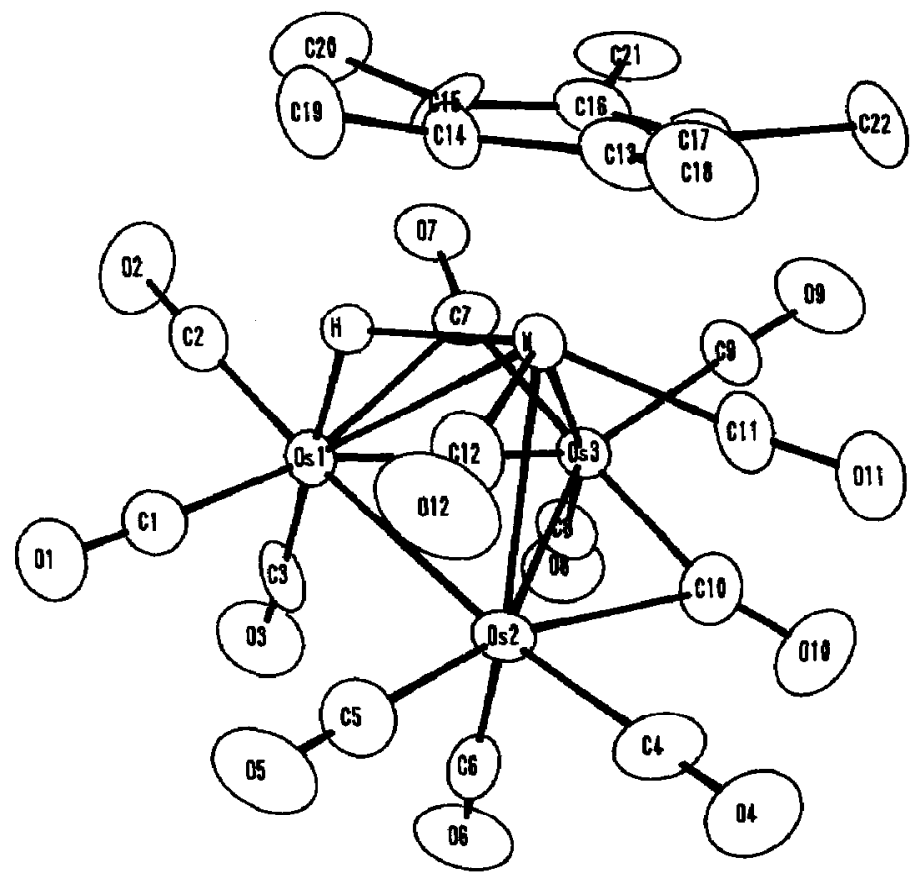

Fig. 1. The molecular structure of $\left(\mathrm{C}_{5} \mathrm{Me}_{5}\right) \mathrm{WOs}_{3}(\mathrm{CO})_{12} \mathrm{H}(2 \mathrm{~b})$ showing the atom numbering scheme.

Table 1

Selected bond distances and bond angles for complex 2

\begin{tabular}{lcll}
\hline Bond distances $(\dot{A})$ & & & \\
Os(1)-Os(2) & $2.8128(12)$ & Os(1)-Os(3) & $2.8231(13)$ \\
Os(2)-Os(3) & $2.8228(14)$ & W-Os(1) & $3.0734(11)$ \\
W-Os(2) & $2.9038(11)$ & W-Os(3) & $2.9074(11)$ \\
W-H & $1.966(15)$ & Os(1)-H & $1.679(13)$ \\
Os(1)-C(1) & $1.889(18)$ & Os(1)-C(2) & $1.895(20)$ \\
Os(1)-C(3) & $1.887(19)$ & Os(2)-C(4) & $1.910(20)$ \\
Os(1)-C(7) & $2.583(17)$ & Os(2)-C(5) & $1.872(19)$ \\
Os(2)-C(6) & $1.906(12)$ & Os(2)-C(10) & $2.510(16)$ \\
Os(2)-C(12) & $2.844(17)$ & Os(3)-C(7) & $1.982(18)$ \\
Os(3)-C(10) & $1.947(17)$ & Os(3)-C(8) & $1.897(20)$ \\
Os(3)-C(9) & $1.896(16)$ & W-C(11) & $2.000(17)$ \\
W-C(12) & $1.983(18)$ & W-C(13) & $2.297(14)$ \\
W-C(14) & $2.311(15)$ & W-C(15) & $2.403(14)$ \\
W-C(16) & $2.406(15)$ & W-C(17) & $2.306(15)$ \\
Bond angles( $\left.{ }^{\circ}\right)$ & & & \\
W-H-Os(1) & & & $177.5(16)$ \\
Os(1)-C(2)-O(2) & $114.7(8)$ & Os(1)-C(1)-O(1) & $176.2(16)$ \\
Os(1)-C(7)-O(7) & $177.8(14)$ & Os(1)-C(3)-O(3) & $176.2(20)$ \\
Os(2)-C(5)-O(5) & $123.9(13)$ & Os(2)-C(4)-O(4) & $176.4(15)$ \\
Os(2)-C(10)-O(10) & $176.5(15)$ & Os(2)-C(6)-O(6) & $159.2(15)$ \\
Os(3)-C(7)-O(7) & $123.3(13)$ & Os(3)-C(10)-O(10) & $176.0(15)$ \\
Os(3)-C(9)-O(9) & $160.9(13)$ & Os(3)-C(8)-O(8) & $174.9(14)$ \\
W-C(12)-O(12) & $178.0(17)$ & W-C(11)-O(11) & $118.9(12)$ \\
\hline
\end{tabular}


$=1.947 \AA$ and $\mathrm{Os}(2)-\mathrm{C}(10=2.510 \AA$. The presence of the last two semi-bridging CO ligands reduces the charge imbalance between the three basal osmium atoms. The formal electron counts for the Os(1), Os(2), and Os(3) atoms are 18.5, 18, and $17 \mathrm{e}^{-}$, respectively.

There is much steric crowding around the pentamethylcyclopentadienyl rings as indicated by the out-of-plane displacement of the methyl groups. The methyl groups of the pentamethylcyclopentadienyl ring have been pushed away from the $\mathrm{WOs}_{3}$ core, and the average displacement from the plane defined by the five center carbons is $0.26(3) \AA$. We propose that this steric effect is responsible not only for the lengthening of the $\mathrm{W}-\mathrm{H}$ distance of the $\mathrm{W}-\mathrm{H}-\mathrm{Os}$ three-center two-electron bond, but also for the reduction of the $2 \mathrm{a} / \mathbf{2 b}$ ratio in comparison with the $\mathbf{1 a} / \mathbf{1 b}$ ratio. As suggested by the structure of 1a, isomer $2 \mathrm{a}$ possesses a bridging $\mathrm{CO}$ ligand associated with an Os-W edge. Because the $\mathrm{CO}$ ligand is larger than the hydride ligand, this $\mathrm{CO}$ ligand would experience an even greater steric repulsion from the $\mathrm{Cp}^{\star}$ group in $2 \mathrm{a}$. Thus, because of the bridging $\mathrm{CO}-\mathrm{Cp}^{\star}$ repulsion in $2 \mathrm{a}$, the $\mathbf{2 a} / \mathbf{2 b}$ ratio is decreased in solution.

Isomers $2 a$ and $2 b$ interconvert rapidly in solution on the NMR time scale above ambient temperature: saturation [6] of the hydride resonance at $\delta-18.22$ results in a $43 \%$ and a $65 \%$ decrease of the intensity of the second resonance at $\delta-20.93$ at $293 \mathrm{~K}$ and $298 \mathrm{~K}$, respectively. The activation parameter was calculated from the variable-temperature ${ }^{1} \mathrm{H}$ NMR data, and the Gibbs energy of activation $\left(\Delta G^{\ddagger}\right)$ calculated from the coalescence of the $\mathrm{CP}^{\star}$ signals is approximately $17.4 \mathrm{kcal} / \mathrm{mole}$ $\left(T_{\mathrm{c}}=355 \mathrm{~K}\right)$. Furthermore, both the temperature and the solvent polarity have little effect on the equilibration constant. The ratio of $2 \mathrm{a} / \mathbf{2 b}$ recorded in THF- $d_{8}$ is $1: 2.2$, identical with that recorded in either $\mathrm{CD}_{2} \mathrm{Cl}_{2}$ or toluene- $d_{8}$.

In an attempt to monitor the exchange of $\mathrm{CO}$ ligands we carried out a variabletemperature ${ }^{13} \mathrm{C}$ NMR study on complex 2 . The ${ }^{13} \mathrm{C}$ NMR spectrum $\left(\mathrm{CD}_{2} \mathrm{Cl}_{2}, 294\right.$ $\mathrm{K})$ of a ${ }^{13} \mathrm{CO}$ enriched sample exhibits a $\mathrm{W}$-CO signal, attributable to isomer $2 \mathrm{a}$, at $\delta 224.2$ with a characteristic $J_{\mathrm{w}-\mathrm{C}}$ coupling $\left(J_{\mathrm{W}-\mathrm{C}}=78 \mathrm{~Hz}\right)$, and shows several uncharacterized Os-CO signals in the area between $\delta 193.4$ and 170.7 emanating from both isomers $2 \mathrm{a}$ and $2 \mathbf{b}$. This $J_{\mathrm{W}-\mathrm{C}}$ coupling constant is very small compared with those of the regular, terminal W-CO ligands which are in the range 140-165 $\mathrm{Hz}$, suggesting that the $\mathrm{W}-\mathrm{CO}$ ligands undergo rapid exchange with the Os-CO ligands. In accord with this assignment, the signal at $\delta 224.2$ broadened and split into a broad signal at $\delta 226.7$ and a sharp signal at $\delta 221.6$ at $173 \mathrm{~K}$. The W-CO signals of isomer $\mathbf{2 b}$ were not observed at room temperature because of the rapid chemical exchange by the $\mathrm{CO}$ ligands. However, when the temperature was decreased to $173 \mathrm{~K}$, two signals of equal intensity at $\delta 212.6\left(J_{\mathrm{w}_{-} \mathrm{C}}=130 \mathrm{~Hz}\right)$ and $207.8\left(J_{\mathrm{W}-\mathrm{C}}=115 \mathrm{~Hz}\right)$, from isomer $2 \mathrm{~b}$, appeared.

Finally, we have also extended the synthesis to the related tungsten-triruthenium complexes, $\mathrm{CpWRu}{ }_{3}(\mathrm{CO})_{12} \mathrm{H}$ and $\mathrm{Cp}^{\star} \mathrm{WRu}_{3}(\mathrm{CO})_{12} \mathrm{H}$ and have determined their solid state structure. Interestingly, these ruthenium complexes adopted a butterfly framework possessing a quadruply bonded $\mathrm{CO}$ ligand [7].

\section{Experimental}

Infrared spectra were recorded on a Perkin-Elmer 580 spectrometer calibrated to the absorption of cyclohexane at $2138.5 \mathrm{~cm}^{-1}$ and the absorption of polystyrene 
film at $1944.5 \mathrm{~cm}^{-1} .{ }^{1} \mathrm{H}$ and ${ }^{13} \mathrm{C}$ NMR spectra were recorded on a Bruker AM-400 (400.13 MHz) instrument. Mass spectra were recorded on a JEOL-HX110 instrument operating in electron impact, field desorption, or fast atom bombardment modes. All reactions were performed under nitrogen in deoxygenated solvents dried with suitable reagents. $\mathrm{Os}_{3}(\mathrm{CO})_{10}\left(\mathrm{CH}_{3} \mathrm{CN}\right)_{2}$ [8] and $\mathrm{Cp}^{\star} \mathrm{W}(\mathrm{CO})_{3} \mathrm{H}$ [9] were prepared by published procedures.

Preparation of $\mathrm{C}_{5} \mathrm{Me}_{5} \mathrm{~W}(\mathrm{CO})_{3} \mathrm{H}$. To solution of $\mathrm{Os}_{3}(\mathrm{CO})_{10}\left(\mathrm{CH}_{3} \mathrm{CN}\right)_{2}$, prepared from $\mathrm{Os}_{3}(\mathrm{CO})_{12}(500 \mathrm{mg}, 0.55 \mathrm{mmol})$ and anhydrous $\mathrm{Me}_{3} \mathrm{NO}(91 \mathrm{mg}, 1.21 \mathrm{mmol})$ in toluene $(40 \mathrm{ml})$, was added a solution of $\left.\mathrm{C}_{5} \mathrm{Me} \mathrm{W}_{5} \mathrm{CO}\right)_{3} \mathrm{H}(600 \mathrm{mg}, 1.48 \mathrm{mmol})$ in toluene $(15 \mathrm{ml})$ dropwise during five minutes. The mixture was then refluxed for 20 minutes until the color had changed from yellow-orange to redbrown. The solvent was then evaporated under vacuum and the residue was separated by thin layer chromatography (silica gel, dichloromethane : hexane $=1: 2$ ). Recrystallization gave $155 \mathrm{mg}$ of 2 as a red crystalline solid $(0.13 \mathrm{mmol}, 24 \%)$. Crystals suitable for X-ray diffraction study were obtained from a layered solution of methanol on dichloromethane at room temperature.

Spectroscopic data: MS (EI, $\left.{ }^{192} \mathrm{Os},{ }^{184} \mathrm{~W}\right), \mathrm{m} / z$ 1232( $\left.M^{+}\right)$; IR $\left(\mathrm{C}_{6} \mathrm{H}_{12}\right) \nu(\mathrm{CO})$ 2087(m), 2086(sh,m), 2069(w), 2053(m), 2047(vs), 2033(vs), 2010(s), 2002(w), 1988(m), 1982(sh, w), 1956(br, vw), 1901(br, vw), 1885(br, vw), 1760(vw) cm ${ }^{-1} ;{ }^{1} \mathrm{H}$ NMR (400 MHz, $\left.\mathrm{CDCl}_{3}, \mathrm{RT}\right) \delta 2.07(\mathrm{~s}, 10.2 \mathrm{H}), 2.01(\mathrm{~s}, 4.8 \mathrm{H}),-18.22(\mathrm{~s}, 0.32 \mathrm{H})$, $-20.93\left(\mathrm{~s}, 0.68 \mathrm{H}, J_{\mathrm{W}-\mathrm{H}}=41 \mathrm{~Hz}\right)$.

Elemental analysis: Found: $\mathrm{C}, 21.53 ; \mathrm{H}, 1.34 . \mathrm{C}_{22} \mathrm{H}_{16} \mathrm{O}_{12} \mathrm{~W}_{1} \mathrm{Os}_{3}$ calcd.: $\mathrm{C}, 21.54 ; \mathrm{H}$, $1.31 \%$.

Structural determination of complex (2). Crystals suitable for diffraction analysis were obtained from dichloromethane-methanol solution. A crystal was mounted on

Table 2

Data for the X-ray diffraction study of complex 2

\begin{tabular}{lcll}
\hline Crystal data & & & \\
$a$ & $21.598(6) \AA$ & Laue symmetry & orthorhombic \\
$b$ & $8.973(4) \AA$ & space group & Pna $2_{1}$ \\
$c$ & $14.121(4) \AA$ & $Z$ & 4 \\
$V$ & $2736.46 \dot{\AA}^{3}$ & Formula & $\mathrm{C}_{22} \mathrm{H}_{16} \mathrm{O}_{12} \mathrm{~W}_{1} \mathrm{Os}_{3}$ \\
mol.wt. & 1226.39 & density (calcd) & $2.978 \mathrm{mg} \mathrm{cm}^{-3}$
\end{tabular}

Data collection, reduction, solution and refinement

data collection instrument

Nonius CAD-4

radiation (monochromated in incident beam)

scan method

scan parameter

$\mathrm{Mo-K}_{a}(\lambda 0.7093 \AA)$

$\theta / 2 \theta$ scan mode

$0.7+0.35 \tan \theta$

crystal size, $\mathrm{mm}$

$0.12 \times 0.22 \times 0.28$

linear absorption coefficient, $\mathrm{mm}^{-1}$

18.24

transmission factors: $\max$, min

$0.998800,0.352100$

no. of unique data, total with $I>3 \sigma(I)$

2507, 2260

no. of atoms and parameters refined

54,343

$R ; R_{w}{ }^{a}$

$0.029 ; 0.018$

$\mathrm{GOF}^{b}$

1.500

residue electron density, e $\dot{A}^{-3}$ : $\max$

0.87

$\bar{a} w=1 / a^{2}\left(F_{\mathrm{o}}\right){ }^{b} s=\left[\sum w\left|F_{\mathrm{o}}-F_{\mathrm{c}}\right|^{2} /\left(N_{\mathrm{o}}-N_{\mathrm{v}}\right)\right]^{1 / 2}\left(N_{\mathrm{o}}=\right.$ number of observations; $N_{\mathrm{v}}=$ number of variables). 
a glass fiber. Diffraction measurements were carried out by use of an Enraf-Nonius CAD-4 fully automated four circle diffractometer. Unit cells were determined and refined from 25 randomly selected reflections, with $2 \theta$ in the range of $15.58-20.52^{\circ}$, obtained by using the CAD-4 automatic search, center, index and least-squares routines. All data reductions and structure refinements were performed by use of the NRCC-SDP-PDP-11 and NRCC-SDP-VAX packages. The structure was solved by the Patterson method and refined by least squares recycle; all non-hydrogen atoms were refined with anisotropic thermal parameters. The hydrogen atoms of the

Table 3

Positions and thermal parameters for complex 2

\begin{tabular}{|c|c|c|c|c|}
\hline Atom & $x$ & $y$ & $z$ & $B$ (iso) ${ }^{a}, \AA^{2}$ \\
\hline $\operatorname{Os}(1)$ & $0.45873(3)$ & $0.53711(7)$ & 0.75000 & $2.45(3)$ \\
\hline$O s(2)$ & $0.41687(3)$ & $0.29875(7)$ & $0.63759(6)$ & $2.51(3)$ \\
\hline $\operatorname{Os}(3)$ & $0.43152(3)$ & $0.25973(7)$ & $0.83468(6)$ & $2.245(24)$ \\
\hline $\mathbf{w}$ & $0.32482(3)$ & $0.42374(6)$ & $0.76496(6)$ & $2.002(24)$ \\
\hline C1 & $0.4608(7)$ & $0.6658(20)$ & $0.6433(13)$ & $3.6(8)$ \\
\hline $\mathrm{C} 2$ & $0.4797(8)$ & $0.6992(20)$ & $0.8298(13)$ & $3.6(8)$ \\
\hline $\mathrm{C} 3$ & $0.5420(9)$ & $0.4796(19)$ & $0.7323(13)$ & $3.9(8)$ \\
\hline $\mathrm{C} 4$ & $0.3752(10)$ & $0.146(3)$ & $0.5678(12)$ & $4.2(9)$ \\
\hline $\mathrm{Cs}$ & $0.4154(8)$ & $0.4175(21)$ & $0.5286(13)$ & $3.7(9)$ \\
\hline C6 & $0.4974(10)$ & $0.2249(19)$ & $0.6084(11)$ & $3.8(10)$ \\
\hline $\mathrm{C} 7$ & $0.4435(8)$ & $0.4338(20)$ & $0.9192(20)$ & $3.5(8)$ \\
\hline $\mathrm{C} 8$ & $0.5124(9)$ & $0.1874(22)$ & $0.8598(10)$ & $3.6(8)$ \\
\hline $\mathrm{Cg}$ & $0.3899(9)$ & $0.1588(21)$ & $0.9340(11)$ & $3.8(8)$ \\
\hline C10 & $0.4168(7)$ & $0.0874(18)$ & $0.7540(13)$ & $3.5(8)$ \\
\hline C11 & $0.2941(7)$ & $0.2196(19)$ & $0.7326(12)$ & $3.3(7)$ \\
\hline C12 & $0.3060(7)$ & $0.4694(20)$ & $0.6303(12)$ & $3.4(8)$ \\
\hline C13 & $0.2218(7)$ & $0.4755(18)$ & $0.7887(9)$ & $2.9(7)$ \\
\hline C14 & $0.2549(7)$ & $0.6153(17)$ & $0.7880(11)$ & $2.7(7)$ \\
\hline C15 & $0.2926(7)$ & $0.6145(17)$ & $0.8735(11)$ & $2.9(7)$ \\
\hline C16 & $0.2827(8)$ & $0.4766(22)$ & $0.9188(11)$ & $3.2(8)$ \\
\hline $\mathrm{C} 17$ & $0.2430(8)$ & $0.3931(17)$ & $0.8679(10)$ & $3.2(7)$ \\
\hline C18 & $0.1711(8)$ & $0.4428(22)$ & $0.7203(11)$ & $4.6(9)$ \\
\hline C19 & $0.2421(9)$ & $0.7491(20)$ & $0.7311(16)$ & $6.0(10)$ \\
\hline $\mathrm{C} 20$ & $0.3242(9)$ & $0.7447(24)$ & $0.9153(13)$ & $5.4(10)$ \\
\hline $\mathrm{C} 21$ & $0.3045(9)$ & $0.4432(22)$ & $1.0207(10)$ & $4.4(9)$ \\
\hline $\mathrm{C} 22$ & $0.2113(8)$ & $0.2467(21)$ & $0.9056(12)$ & $3.9(8)$ \\
\hline O1 & $0.4621(8)$ & $0.7469(15)$ & $0.5819(9)$ & $6.9(9)$ \\
\hline $\mathbf{O} 2$ & $0.4930(7)$ & $0.7951(15)$ & $0.8809(9)$ & $5.8(7)$ \\
\hline O3 & $0.5934(6)$ & $0.4529(17)$ & $0.7220(9)$ & $6.5(8)$ \\
\hline 04 & $0.3490(8)$ & $0.0640(19)$ & $0.5259(10)$ & $6.8(8)$ \\
\hline 05 & $0.4112(6)$ & $0.4889(16)$ & $0.4610(8)$ & $5.6(7)$ \\
\hline 06 & $0.5455(7)$ & $0.1742(19)$ & $0.5940(9)$ & $5.6(8)$ \\
\hline 07 & $0.4456(5)$ & $0.5062(15)$ & $0.9869(7)$ & $3.9(6)$ \\
\hline 08 & $0.5594(6)$ & $0.1389(16)$ & $0.8787(9)$ & $5.1(7)$ \\
\hline 09 & $0.3661(7)$ & $0.0944(18)$ & $0.9942(10)$ & $6.6(8)$ \\
\hline 010 & $0.4071(7)$ & $-0.0374(13)$ & $0.7324(10)$ & $6.0(8)$ \\
\hline 011 & $0.2724(6)$ & $0.1064(14)$ & $0.7167(9)$ & $5.4(7)$ \\
\hline 012 & $0.2841(6)$ & $0.4944(17)$ & $0.5579(8)$ & $5.4(8)$ \\
\hline $\mathrm{H}$ & 0.368 & 0.583 & 0.781 & 3.2 \\
\hline
\end{tabular}

a $B$ (iso) is the mean of the principle axes of the thermal ellipsoid. 
methyl group were added at the idealized positions and were included in the structure factor calculations; the hydride hydrogen was located on the difference electron density map. The data collection parameters and the atomic coordinates are summarized in Tables 2 and 3. Tables of anisotropic thermal parameters, structure factor amplitudes, and non-essential bond distances and angles are available from the authors (S.M.P.).

\section{Acknowledgement}

This work was supported by the National Science Council of the Republic of China.

\section{References}

1 W.L. Galdfelter and G.L. Geoffery, Adv. Organomet. Chem., 18 (1980) 207.

2 (a) M.R. Churchill, C. Bueno, W.L. Hsu, J.S. Plotkin and S.G. Shore, Inorg. Chem., 21 (1985) 1958. (b) D.T. Eadie, H.D. Holden, B.F.G. Johnson and J. Lewis, J. Chem. Soc., Dalton Trans., (1984) 301. (c) R.D. Adams, I.T. Horvâth and B.E. Segmüller, Organometallics, 1 (1982) 1537. (d) M.R. Churchill, C. Bueno, S. Kennedy, J.C. Bricker, J.S. Plotkin and S.G. Shore, Inorg. Chem., 21 (1982) 627. (e) J.S. Plotkin, D.G. Alway, C.R. Weisenbreger and S.G. Shore, J. Am. Chem. Soc., 102 (1980) 6156. (f) L.Y. Hsu, W.L. Hsu, D.Y. Jan, A.G. Marshall and S.G. Shore, Organometallics, 3 (1984) 591. (g) M. Castiglioni, R. Giordano and E. Sappa, J. Organomet. Chem., 258 (1983) 217. (h) G. Süss-Fink, U. Thewalt and H.P. Klein, J. Organomet. Chem., 262 (1984) 315. (i) L. Busetto, M. Green, J.A.K. Howard, J.C. Jeffery and F.G.A. Stone, J. Chem. Soc., Dalton Trans., (1983) 519. (j) M.R. Churchill, C. Bueno, J.T. Park and J.R. Shapley, Inorg. Chem., 23 (1984) 1017.

3 M.R. Churchill, F.J. Hollander, J.R. Shapley and D.S. Foose, J. Chem. Soc. Chem. Commun., (1978) 534.

4 Y. Chi, L.-S. Hwang, G.-H. Lee and S.-M. Peng, J. Chem. Soc. Chem. Commun., (1988) 1456.

5 (a) F.A. Cotton, Prog. Inorg. Chem., 21(1976) 1. (b) R. Colton and J.M. McCormick, Coord. Chem. Rev., 31 (1980) 1. (C) C.P. Horwitz and D.F. Shriver, Adv. Organomet. Chem., 23 (1984) 219.

6 M.L. Martin, G.J. Martin and J.-J. Delpuech, Practical NMR Spectroscopy; Heyden \& Sons Inc., Philadelphia, PA, 1980, pp 315-320.

7 Y. Chi, F.-J. Wu, B.J. Liu, C.-C. Wang and S.-L. Wang, submitted to J. Chem. Soc., Chem. Commun., in press.

8 B.F.G. Johnson, J. Lewis and A.P. David, J. Chem. Soc., Dalton Trans., (1981) 407.

9 G.J. Kubas, H.J. Wasserman and R.R. Ryan, Organometallics, 4 (1985) 2012. (b) G.J. Kubas, Inorg. Chem., 22 (1983) 692. 